\title{
Feasibility of Direct Mapping of Cerebral Fluorodeoxy-D-Glucose Metabolism In Situ at Subcellular Resolution Using Soft $\mathrm{X}$-Ray Fluorescence
}

\author{
Carole Poitry-Yamate, ${ }^{1,2 \star}$ Alessandra Gianoncelli, ${ }^{3}$ Burkhard Kaulich, $, 3,4$ \\ George Kourousias, ${ }^{3}$ Arthur W. Magill, ${ }^{1}$ Mario Lepore, ${ }^{1}$ Vincent Gajdosik, ${ }^{5}$ \\ and Rolf Gruetter ${ }^{1,2,6}$ \\ ${ }^{1}$ Institute of Physics of Biological Systems-Biomedical Imaging Center (CIBM), \\ Ecole Polytechnique Fédérale de Lausanne (EPFL), Lausanne, Switzerland \\ ${ }^{2}$ Radiology Department, University of Lausanne, Lausanne, Switzerland \\ ${ }^{3}$ ELETTRA-Sincrotrone Trieste S.C.p.A., Trieste, Basovizza, Italy \\ ${ }^{4}$ Diamond Light Source Ltd., Harwell Science and Innovation Campus, Didcot, \\ Oxfordshire, United Kingdom \\ ${ }^{5}$ Division of Medical Radiation Physics, Bern University Hospital, Bern, Switzerland \\ ${ }^{6}$ Radiology Department, University of Geneva, Geneva, Switzerland
}

\begin{abstract}
Glucose metabolism is difficult to image with cellular resolution in mammalian brain tissue, particularly with ${ }^{18}$ fluorodeoxy-D-glucose (FDG) positron emission tomography (PET). To this end, we explored the potential of synchrotron-based low-energy X-ray fluorescence (LEXRF) to image the stable isotope of fluorine $(F)$ in phosphorylated FDG (DG-6P) at $1 \mu \mathrm{m}^{2}$ spatial resolution in 3- $\mu \mathrm{m}$-thick brain slices. The excitation-dependent fluorescence $\mathrm{F}$ signal at $676 \mathrm{eV}$ varied linearly with FDG concentration between 0.5 and $10 \mathrm{mM}$, whereas the endogenous background $F$ signal was undetectable in brain. To validate LEXRF mapping of fluorine, FDG was administered in vitro and in vivo, and the fluorine LEXRF signal from intracellular trapped FDG-6P over selected brain areas rich in radial glia was spectrally quantitated at $1 \mu \mathrm{m}^{2}$ resolution. The subsequent generation of spatial LEXRF maps of $\mathrm{F}$ reproduced the expected localization and gradients of glucose metabolism in retinal Müller glia. In addition, FDG uptake was localized to periventricular hypothalamic tanycytes, whose morphological features were imaged simultaneously by X-ray absorption. We conclude that the high specificity of photon emission from $F$ and its spatial mapping at $\leq 1 \mu \mathrm{m}$ resolution demonstrates the ability to identify glucose uptake at subcellular resolution and holds remarkable potential for imaging glucose metabolism in biological tissue. $\odot 2012$ Wiley Periodicals, Inc.
\end{abstract}

Key words: fluorodeoxy-D-glucose; low-energy X-ray fluorescence spectromicroscopy; periventricular hypothalamus; radial glia; retina; synchrotron

Glucose metabolism is essential to brain function because it is the predominant substrate that indirectly supports all energy requiring activities of the mammalian brain. Glucose's role in maintaining brain function is exemplified by regional increases in neuronal activity that are correlated with increases in glucose metabolism, implying that a rapid and effective modulation of glucose metabolism is occurring during and following functional responses to neural stimulation (Phelps, 2000). This correlation makes ${ }^{18}$ fluorodeoxy-D-glucose (FDG) PET imaging the gold standard in the noninvasive evaluation of brain metabolism.

When 2-deoxy-D-glucose (DG) is used, its uptake and subsequent phosphorylation yield 2-deoxy-D-glucose-6-phosphate (DG-6P), which is trapped in the metabolically active cell at concentrations that can reach micromoles per gram, detectable by nuclear magnetic resonance (NMR; Cohen et al., 2002). Patterns of regional DG utilization have been measured in brain autoradiographs using either ${ }^{14} \mathrm{C}$ or ${ }^{3} \mathrm{H}$ (Sokoloff et al., 1977). These methods are largely limited by the mean free path length of $\beta$ particles (Knoechel and Kalff, 1976; cf. Caro et al., 1962; Caro, 1962), so DG6P

Contract grant sponsor: Integrated Infrastructure Initiative "European Light Sources Activities-Synchrotrons and Free Electron Lasers"; Contract grant number: RII3-CT-2004-506008 (to C. P.-Y); Contract grant sponsor: CIBM of the UNIL, UNIGE, CHUV, HUG, EPFL, and the Leenaards and Jeantet Foundations; Contract grant sponsor: Swiss National Science Foundation; Contract grant number: 131087 (to R.G.).

*Correspondence to: C. Poitry-Yamate, Biomedical Imaging Center (CIBM), Ecole Polytechnique Fédérale de Lausanne, Station 6, CH-1015 Lausanne, Switzerland. E-mail: carole.poitry-yamate@epfl.ch

Received 13 July 2012; Revised 3 October 2012; Accepted 11 October 2012

Published online 14 December 2012 in Wiley Online Library (wileyonlinelibrary.com). DOI: 10.1002/jnr.23171 
imaging in adult mammalian CNS is generally limited to length scales prohibiting cellular resolution, with a few exceptions (Ryan and Sharp, 1982; Poitry-Yamate and Tsacopoulos, 1991; Nehlig et al., 2004). However, central to understanding the mechanism of the tripartite synapse, i.e., presynaptic and postsynaptic neuron as well as glial processes (Smith, 2010), the physiological mechanisms underlying in vivo ${ }^{18} \mathrm{FDG}$ PET neuroimages (Frackowiak et al., 2002), and the cell specificity of glucose metabolism, which has not yet been completely established (Chih et al., 2001), requires measurements at micrometer resolution.

To image the structurally identical molecule, albeit nonradiolabeled, i.e., ${ }^{19} \mathrm{~F}$ in FDG-6P with subcellular spatial resolution, we explored the potential of synchrotron-based low-energy X-ray fluorescence (LEXRF). With synchrotron based X-ray microspectroscopy, micrometer spatial resolution is achievable (see, e.g., David et al., 2000; Kaulich et al., 2011). X-ray fluorescence (XRF) imaging is based on the XRF emission, unique for each element of the periodic table, irradiated with X-rays of sufficient energy that results in the removal of core electrons. Therefore, the XRF spectrum contains information on the abundance of a specific elemental constituent in the specimen. The advantage of using a synchrotron X-ray source is its high brightness and tunabilty, so the X-ray energy can be optimized to provide high fluorescence yield from the element under investigation (Müller, 1972; Ide-Ektessabi, 2007; Ortega et al., 2007). Use of an X-ray microprobe and scanning the specimen allows mapping of the elemental spatial distribution (Kaulich et al., 2011). This approach, however, has not been applied to brain energy metabolism, particularly exogenous fluorine (F) in FDG, because of F's inherently low fluorescence yields and low interaction cross-section and the limited penetration depth of lowenergy incident X-ray light in biological tissue (Streli et al., 1999; Hoefler et al., 2006).

The aim of the present study was to develop and validate the capability of synchrotron-based LEXRF to image $\mathrm{F}$ in phosphorylated FDG with subcellular resolution. First, we were able to reproduce previous findings of FDG uptake into the retina, known for its laminar structure, allowing us to localize glucose metabolism to radial Müller glial cells (Poitry-Yamate and Tsacopoulos, 1991). Second, to determine whether such gradients in glucose uptake matching glial density can also be observed in other brain regions, we assessed FDG metabolism in the periventricular hypothalamus, also a highly laminar structure, containing the radial tanycytes that line the hypothalamus-third ventricle interface.

\section{MATERIALS AND METHODS}

All animal experiments were conducted according to federal and local ethical guidelines, and the protocols were approved by the local regulatory body of the Canton Vaud, Switzerland (Service de la Consommation et des Affaires Vétérinaires, Affaires Vétérinaires, Canton de Vaud, Suisse). All chemicals were purchased from Sigma-Aldrich (Buchs, Switzerland).

\section{DG-6P Bioenzymatic Assay}

The 1:1 stoichiometry between $\mathrm{F}$ and DG-6P allowed estimating the concentration of fluorine in FDG-6P in brain samples subsequent to FDG administration by enzymatically converting FDG-6P back to FDG. The FDG produced in this reaction was then assayed spectrophotometrically at $560 \mathrm{~nm}$ using a previously established procedure based on Trinder's method (Poitry-Yamate et al., 2009). Briefly, to confirm the activity of G6Pase to degrade DG-6P to DG, we started with standards of D-glucose-6P. Standards were exposed to $5 \mathrm{U}$ G6Pase for $10 \mathrm{~min}(\mathrm{pH} 7.5)$ at $30^{\circ} \mathrm{C}$ with shaking. D-glucose from these samples and D-glucose standards were then bioassayed spectrophotometrically at $560 \mathrm{~nm}$ using glucose oxidase. The concentration of D-glucose-6P was calculated from the difference between the absorbance values with or without G6Pase in the assay. Spectrophotometric measurements were then performed using standards of DG-6P and FDG and retinal samples that had not been frozen prior to enzymatic measurements.

\section{FDG Uptake Experiments}

In vitro. Retinae, excised from the eyes of SpragueDawley rats $(\sim 300 \mathrm{~g})$ anesthetized with isoflurane (4\%) followed by pentobarbital $(65 \mathrm{mg} / \mathrm{kg})$, were transferred to bicarbonate-buffered Ringer's solution (BBRS) carrying $5 \mathrm{mM}$ D-glucose $\left(37^{\circ} \mathrm{C}, \mathrm{pH} 7.4\right)$ and then light and dark adapted in parallel (Poitry-Yamate and Tsacopoulos, 1991). After $60 \mathrm{~min}$, quarters of retinae were briefly washed to remove D-glucose and then exposed to $10 \mathrm{mM}$ FDG for $50 \mathrm{~min}$. Thereafter, metabolism was stopped and nonphorphorylated FDG removed by washing the preparations in $3 \times 600 \mu$ l chilled BBRS.

In vivo. Three in vivo FDG experiments were performed using Sprague-Dawley rats on a dedicated small-animal APD-based PET scanner (Gamma Medica, Sherbrook, Ontario, Canada) following a bolus delivery i.v. of ${ }^{19} \mathrm{FDG}$ $(2 \mathrm{~g} / \mathrm{kg})$ under pentobarbital anesthesia in place of ${ }^{18} \mathrm{FDG}$. ${ }^{18}$ FDG PET was performed in another set of rats under identical conditions to confirm DG uptake and phosphorylation.

\section{Tissue Fixation}

For Figure 2, preparations were immersed in $4 \%$ formalin in Dulbecco's phosphate-buffered saline (DPBS). For Figures 1 and 3, preparations were frozen flat in a custommade, well support immersed in isopentane, cooled in liquid nitrogen, then lyophylized $\left(10^{-4}\right.$ mbars). For Figure $4,4 \%$ formalin in chilled $0.9 \% \mathrm{NaCl}$ was perfused through the myocardial left ventricle. The animal was decapitated, and the brain was removed and transferred to $4 \%$ formalin in DPBS. All preparations were briefly washed in DPBS to remove excess formalin prior to dehydration.

\section{Planar Specimen Surfaces}

Over the course of 5 days, slices of brain tissue, following chemical fixation, were dehydrated in a series of increasing 


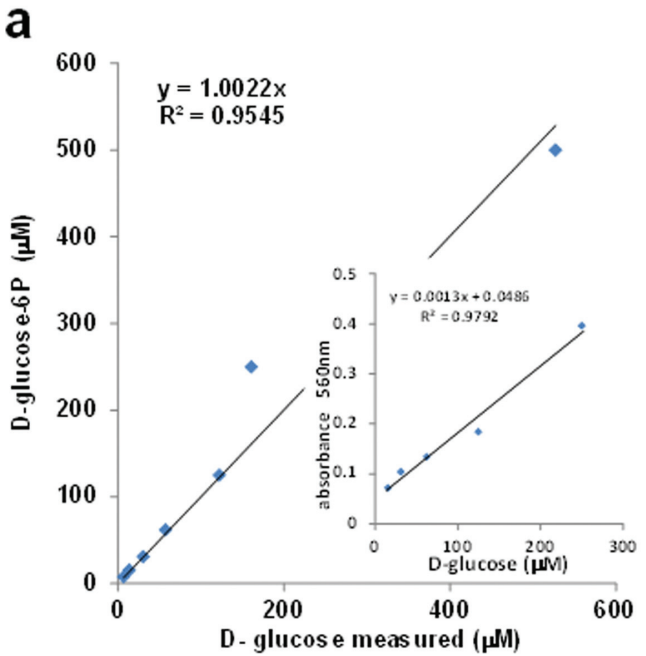

Fig. 1. Bioenzymatic determination of fluorine in FDG-6P. a: Standards of D-glucose-6P ranging from 7.8 to $500 \mu \mathrm{M}$ were linearly related to the concentration of D-glucose produced in the reaction with G6Pase followed by glucose oxidase. Inset: Calibration curve of absorbance values used to calculate D-glucose concentration. b:

acetone (in percentage: $30 \times 4,50 \times 4,70 \times 5,90 \times 5$, and $100 \times 5,20 \mathrm{~min}$ each), then infiltrated in a series of increasing Epon (acetone:Epon 3:1, 1:1, 1:3, and 0:3) prepared for maximum hardness to minimize radiation damage (Fayard et al., 2009; Meents et al., 2010). Brain slices were then oriented, and Epon polymerization was performed at $70^{\circ} \mathrm{C}$ for 2 days. Tissue blocks were shaped and then sectioned to $3 \mu \mathrm{m}$ thickness on a conventional ultramicrotome, removing undesirable topographical information at the sample surface (Penner-Hahn, 2000).

\section{FDG Standards for LEXRF Measurements}

FDG standards equivalent to $0.5,1,3,5$ and $10 \mathrm{mM}$ were prepared at the Laboratory for Interdisciplinary Lithography at ELETTRA by spin coating FDG in tetrahydrofuran (THF) or FDG in polymethyl methacrylate (PMMA) in dimethylsulfoxide onto silicon nitride membrane windows. Standards were then air dried, producing a transparent membrane film $\sim 3 \mu \mathrm{m}$ in thickness.

\section{Twinmic Beamline Configuration for LEXRF of $F$}

X-ray measurements were performed at $907 \mathrm{eV}$ with a $0.6-\mu \mathrm{m}$-diameter $\mathrm{X}$-ray microprobe delivered by a $320-\mu \mathrm{m}-$ diameter Fresnel zone plate with an outermost zone width of $50 \mathrm{~nm}$. X-ray fluorescence photon emission was detected by four silicon drift detectors (SDDs) in an annular configuration (Kaulich et al., 2006; Alberti et al., 2009; Gianoncelli et al., 2009). The sample preparation was raster-scanned with respect to the microprobe, simultaneously collecting the emitted and transmitted photons. To characterize the morphology of the specimen, scanning transmission X-ray microscopy (STXM) imaging was performed in both absorption and phase-contrast modes and acquired by a CCD camera. LEXRF map areas

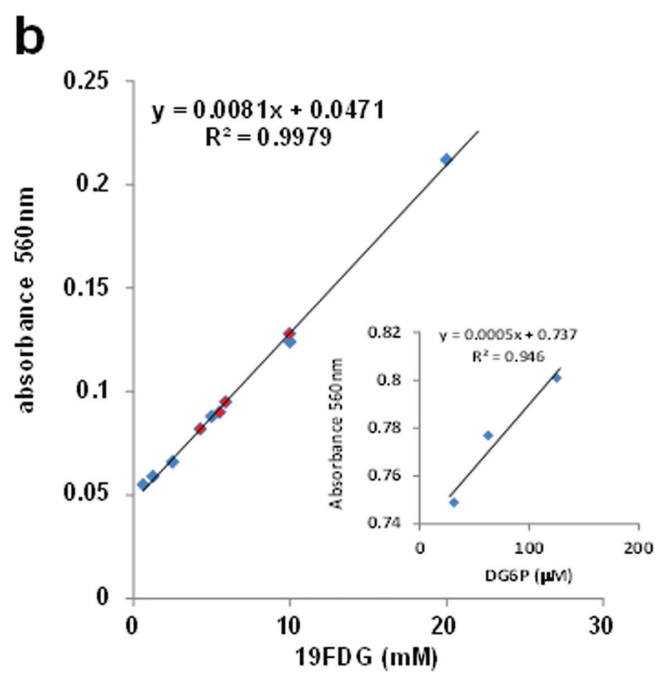

Standards of FDG ranging from 0.625 to $20 \mathrm{mM}$ (blue lozenges) were linearly related to absorbance of resorufin at $560 \mathrm{~nm}$ in the presence of reagent. Concentrations of FDG-6P determined from four retinae are shown in blue. Inset: Sandards of DG-6P were linearly related to absorbance at $560 \mathrm{~nm}$.

ranged between 600 and $1,100 \mu^{2}$ (600-1,100 pixels ${ }^{2}$ ), with dwell times between 45 and $60 \mathrm{sec} /$ pixel.

\section{LEXRF Analysis}

Deconvolution of the fluorescence spectrum for each pixel was performed using the PyMCA Hypermet algorithm and constant baseline substraction (Solé et al., 2007). The K $\alpha$ emissions for C, N, O, F, and elastic scattering (EO) lines were monitored. In this article, only the fits for $\mathrm{C}, \mathrm{N}, \mathrm{O}$, and $\mathrm{F}$ are shown. To verify that the small to negligible contribution of iron (probably below the beamline detection limits) did not affect the fitting of $\mathrm{F}$, an earlier fitting procedure included the emission energy of Fe L $\alpha(705 \mathrm{eV})$. The measured F fluorescence yield was 0.010 , and the Fe fluorescence yield was half that of F. The extracted peak heights for $\mathrm{C}, \mathrm{O}, \mathrm{N}$, and $\mathrm{F}$ were normalized with respect to the beam current over the course of the LEXRF scan. To compare F photon signal intensities from one region to another in $\mathrm{F}$ maps, the $\mathrm{F}$ photon signal was further normalized with respect to the beam current of the first pixel of the scan. In Figures 2-4, spectra profiles of normalized photon counts as a function of emission energy represent the average of four spectra taken from four individual pixels in a $2 \mu \mathrm{m} \times 2 \mu \mathrm{m}(2$ pixel $\times 2$ pixel $)$ array. The location of the array is denoted in the absorption images (Fig. 2) or by the numbers indicated in the LEXRF F maps (Figs. 3c, 4b).

\section{RESULTS}

To determine the amount of FDG-6P, retinal samples were analyzed by using biochemical methods (Poitry-Yamate et al., 2009) prior to LEXRF detection of F. Standards of known concentrations of D-glucose$6 \mathrm{P}$ were first subjected to a sequential enzymatic reaction using G6Pase, followed by glucose oxidase. As 

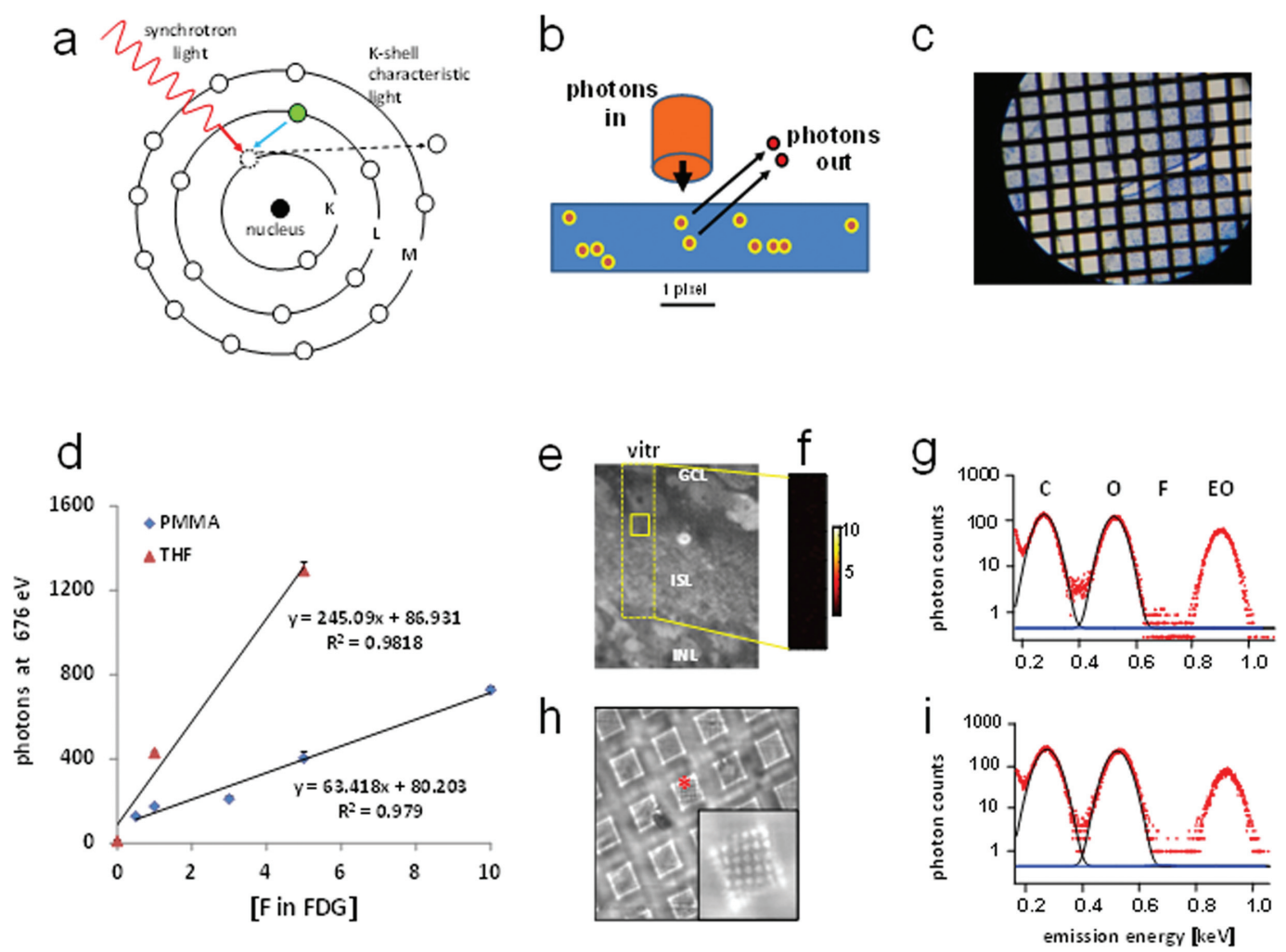

Fig. 2. Principles of $\mathrm{X}$-ray fluorescence and detection of $\mathrm{F}$ in controls. a:A core K-shell electron is ejected from the $\mathrm{F}$ atom upon $\mathrm{X}$ ray excitation by synchrotron light. The created vacancy is filled by a higher (L) shell electron, a process that results in the emission of a fluorescent $F$ photon specifically at $676 \mathrm{eV}$. b: The photoelectric effect in a relative to the biological specimen (blue) is a "photon in" (excitation)-"photon out" (emission) phenomenon. The emitted photons from $\mathrm{F}$ (yellow outlined red dots) are collected by energy dispersive detectors for multielement analysis. The 1- $\mu \mathrm{m}$-diameter photon beam (orange) is stationary, so the sample is raster-scanned with respect to the microprobe, simultaneously collecting the emitted and transmitted photons. One photon-energy emission spectral map, low energy X-ray fluorescence (LEXRF) Z elemental maps, and a scanning transmission X-ray image (STXM) in absorption and phase-contast mode are recorded pixel by pixel to build gradually a complete map of the selected brain area. c: Epon-embedded brain sections, e.g., periventricular hypothalamus shown, were mounted onto gold electron microscopic grids previously centered over holes

shown in Figure 1a, the concentration of D-glucose produced in the enzymatic reactions varied linearly as a function of the starting concentration of D-glucose-6P. This enzymatic bioassay was also inherently sensitive to FDG (Fig. 1b). The amount of $\mathrm{F}$ from four retinae calculated from absorbance values of FDG with or without G6Pase in the assay is shown in Figure 1b (red lozenges), averaging $6.4 \pm 1.23 \mathrm{mM}$.

The emission of fluorescent photons by $\mathrm{F}$ is consequent to the atom's excitation with incident photons that eject F core-shell electrons, i.e., photoelectric effect, as illustrated in Figure $2 \mathrm{a}$ using the Bohr atom model and in Figure $2 b$, relative to X-ray illumination of the in a molybdenum plate (in black). Scale: $100 \mu \mathrm{m} \times 100 \mu \mathrm{m}$ per grid square. d: Detector response to $0.5,1,3,5$, and $10 \mathrm{mM}$ FDG, prepared using two different solvents. Measurements were performed in triplicate (for PMMA) and quadruplicate (for THF) and expressed as the average number of photons emitted at $676 \mathrm{eV} \pm$ SEM. e: STXM image of a retinal preparation (inner half) previously exposed to D-glucose in place of FDG. The dashed yellow outline measures $10 \mu \mathrm{m} \times 60 \mu \mathrm{m}$. f: Ten pixel $\times 60$ pixel LEXRF map of $\mathrm{F}$ obtained from the area indicated in e. g: Spectral profile of K $\alpha$ emission for $\mathrm{C}, \mathrm{N}, \mathrm{O}, \mathrm{F}$, and elastic scattering (EO) averaged from the solid boxed area indicated in e. Note that $\mathrm{F}$ at $676 \mathrm{eV}$ was indistinguishable from the detector noise. h: STXM image of the epon matrix, $3 \mu \mathrm{m}$ in thickness, overlying the gold EM grid (in focus). Inset: Epon layer, post-LEXRF scanned, is in focus to show the $5 \mu \mathrm{m} \times 5$ $\mu \mathrm{m}(5$ pixel $\times 5$ pixel $)$ irradiated area. i: Averaged, normalized energy emission spectra from the area scanned in $h$. Note the absence of an F signal.

specimen. In this study, an incident photon flux of $\sim 2$ $\times 10^{11}$ photons/sec/100 mA and photon energy of $\sim 907 \mathrm{eV}$ (or wavelength $<10 \mathrm{~nm}$ ) was focused to a 1$\mu \mathrm{m}$-diameter spot on the surface of the specimen, whose configuration on the microscope stage is shown in Figure 2c. The incident X-ray photon energy was selectively matched to the inner shell electron energies of $F$, in addition to other low- $\mathrm{Z}$ elements of biological interest, i.e., $\mathrm{C}, \mathrm{O}$, and $\mathrm{N}$, thereby covering an energy range from 200 to $1,000 \mathrm{eV}$. Under these conditions, the number of fluorescent photons emitted at $676 \mathrm{eV}$ was determined from FDG standards. Independent of solvent, $\mathrm{F}$ was linearly related to the concentration of $\mathrm{F}$ in 

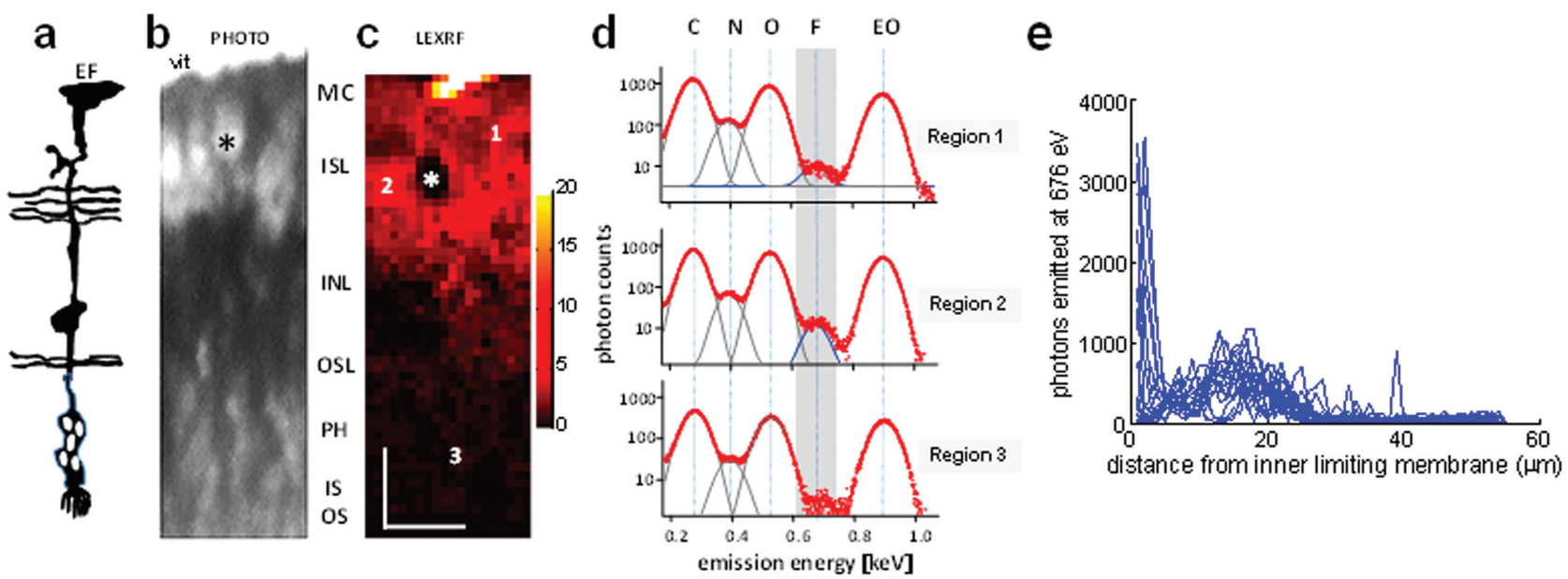

distance from inner limiting membrane ( $\mu \mathrm{m})$

Fig. 3. Retinal glucose metabolism imaged under stimulated conditions at $1 \mu \mathrm{m}^{2}$ resolution. a: Morphology of a single Müller glial cell in relation to its position in situ, scaled and oriented with respect to b and c. b: Photomicrograph of the area adjacent to the retinal area scanned for F. Scaled to map in c. c: LEXRF map of F in FDG-6P from the inner (top) to outer (bottom) retinal layers. d: Spectra profiles of $\mathrm{K} \alpha$ emission for $\mathrm{C}, \mathrm{O}, \mathrm{N}, \mathrm{F}$, and elastic scattering (EO) from regions 1-3 indicated in c. Dwell time $47 \mathrm{sec} /$ pixel. e: $\mathrm{F}$ signal as a function of distance from the inner limiting membrane, separating the vitreous from the inner retinal surface. $F$ signal is expressed as the number of photons emitted after normalization with respect to the beam current. MC, Müller cell endfeet layer; ISL, inner synaptic layer; INL, inner nuclear layer; OSL, outer synaptic layer; PH, photoreceptor soma layer; IS, inner photoreceptor segment layer; OS, outer photoreceptor segment layer. Scale bar $=10 \mu \mathrm{m}$.

FDG, reaching a detection limit at $0.5 \mathrm{mM}$ (Fig. 2d). In contrast, the $\mathrm{K} \alpha$ emission for $\mathrm{F}$ at $676 \mathrm{eV}$ was indistinguishable from the detector noise when measured from the Epon matrix that displaced water in the brain samples (Fig. 2h,i) and from retinae not previously exposed to FDG (Fig. 2e,g). This result demonstrated that no F background signal in brain tissue would complicate the $\mathrm{X}$-ray fluorescence analysis, i.e., that $\mathrm{F}$ detected is from the FDG administered.

To reproduce previous experimental findings demonstrating that glucose uptake in the mammalian retina is localized predominantly to radial glia (Fig. 3a), we measured the $\mathrm{X}$-ray fluorescence $\mathrm{F}$ signal subsequent to FDG uptake in five dark-adapted retinae (Fig. 3b) known to have high excitatory synaptic transmission. FDG-6P decreased with decreasing glial content, illustrated by the LEXRF $F$ (photon) signals (Fig. 3d) obtained from regions $1-3$, resulting in a diffuse $F$ map (Fig. 3c) in the photoreceptor layer ( $\mathrm{PH}$; region 3). In contrast, the inner synaptic layer (ISL) and Müller cell layer $(\mathrm{MC})$, rich in prominent glial endfeet (region 1 at the vitreous-retinal interface, and perivascular in region 2), exhibited high uptake and phosphorylation of FDG, with a clearly discernible $\mathrm{F}$ signal in the energy emission spectra (Fig. 3d). The F map indicates finger-like branching structures and large patches of $F$ surrounding a blood vessel (indicated by an asterisk in Fig. 3b,c). Similarly, FDG uptake and phosphorylation from one endfoot (EF; Fig. 3a) to another along the retinal vitreous interface (parallel to the inner retinal surface) was comparable to that of region 1 (Fig. 4). When the X-ray fluorescence photon signal at $676 \mathrm{eV}$ was plotted from
Fig. 4. Glucose metabolism by Müller glial endfeet at the retinal-vitreous interface. a: Photomicrograph of the retina identifying the area scanned for $\mathrm{F}$ (in yellow) and individual retinal layers. Note the cell endfeet in dark blue at the top arrow. b: LEXRF map of normalized F in FDG-6P, corresponding to the left half of the scanned area. c: LEXRF map of F in FDG-6P, corresponding to the entire scanned area. Scale bar same as in $\mathrm{b}$. The dashed box highlights the area scanned in b. d: F signal as a function of distance from the vitreous. Note that in $\mathrm{c}$ and $\mathrm{d}$ the $\mathrm{F}$ signal has been expressed as the number of photons emitted after normalization with respect to only the beam current. 


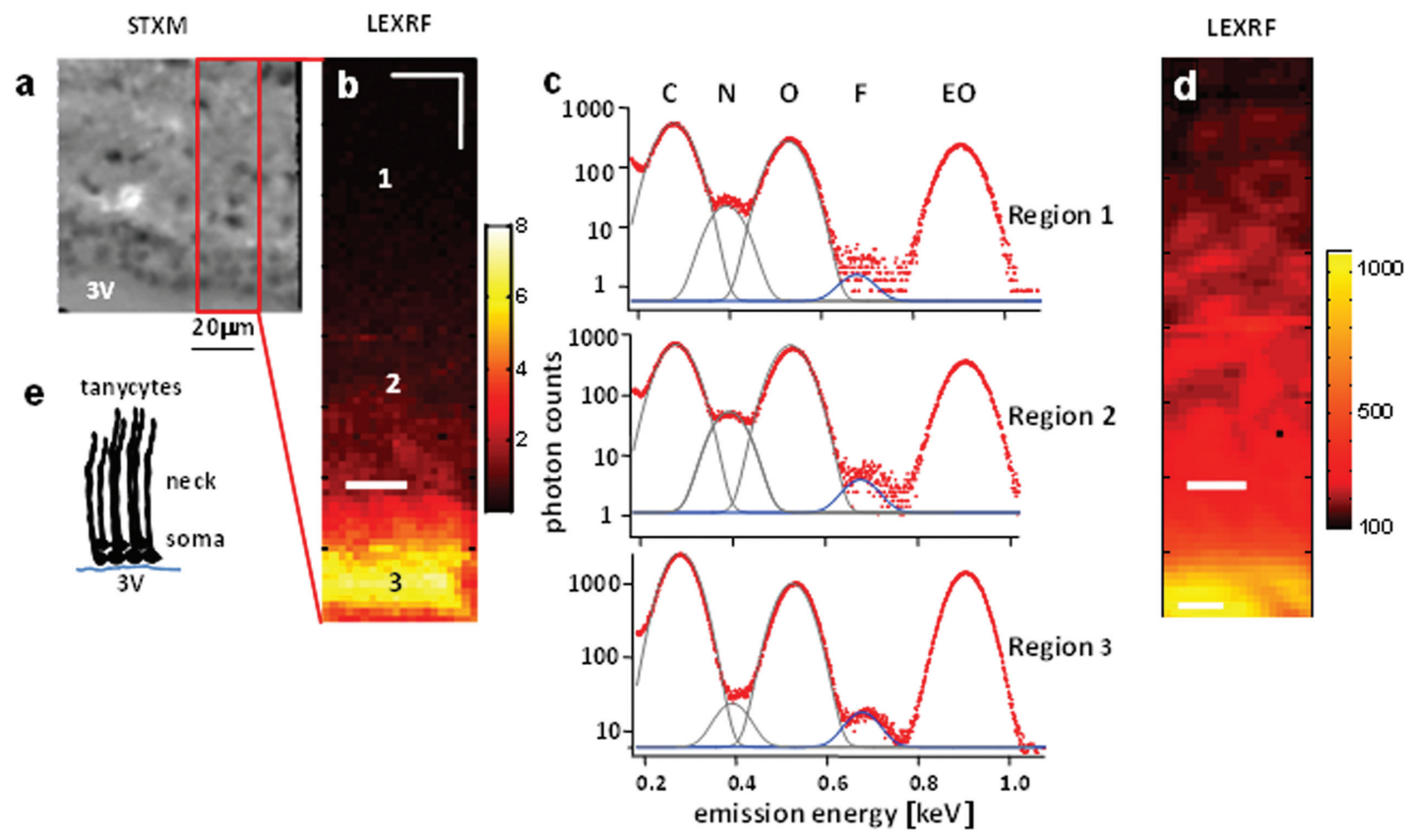

Fig. 5. Glucose metabolism imaged at the hypothalamus-third ventricule interface. a: STXM image of the hypothalamus along the lower lateral wall of the third ventricle $(3 \mathrm{~V})$. b: LEXRF map of $F$ in FDG6P acquired from the red area outlined in a. Dwell time $45 \mathrm{sec} /$ pixel. c: Spectra profiles of $\mathrm{K} \alpha$ emission for $\mathrm{C}, \mathrm{N}, \mathrm{O}, \mathrm{F}$, and $\mathrm{EO}$ from the three regions indicated in $\mathrm{b}$. d: LEXRF map of $\mathrm{C}$ acquired in parallel with that of $\mathrm{F}$ of the area indicated in a. The upper half of the $\mathrm{C}$ map shows a high signal in the neuronal cytoplasm resulting from water being displaced by epon, and thus generally low contrast. e: Morphology of an individual hypothalamic radial glial cell (tanycyte) relative to the in situ position in a. Scale bars $=20 \mu \mathrm{m}$ in a; 10 $\mu \mathrm{m}$ in $\mathrm{b}, \mathrm{d}$. the inner retinal surface (inner limiting membrane) to the outer retina (Fig. 3e; equivalent to plotting the $\mathrm{F}$ photon signal per pixel of the LEXRF map by column), the $\mathrm{F}$ gradient was shown to parallel glial cell density. Notice the dip between 10 and $15 \mu \mathrm{m}$ from the inner retinal surface in Figure 3e that corresponds to the location of a blood vessel.

To determine $\mathrm{F}$ uptake in the hypothalamus, known for its laminar structure of tanycytes, leading to a gradient in glial cell density similar to that of the retina (see above), we infused FDG into three live animals. After $50 \mathrm{~min}$, anesthetized animals were perfused with formalin through the myocardial left ventricle. FDG metabolism, when quantitated at and distal to the hypothalamus-ventricle interface (Fig. 5a), showed that FDG-6P decreased with increasing distance from the ventricle (regions 1-3 in Fig. 5b), reaching detection limits (Fig. $5 c$, region 1) in areas rich in neurons (Fig. $5 \mathrm{~d}$ ). In contrast, FDG uptake and phosphorylation increased toward the ventricle wall and was disproportionately high in region 3 (Fig. 5b,c), corresponding to dense, multiple rows of cell somata of tanycytes (Fig. $5 \mathrm{a}, \mathrm{e}$ ).

\section{DISCUSSION}

The present article describes for the first time the adaptation and use of synchrotron-based LEXRF to image a biochemical and metabolic process of major importance, i.e., glucose metabolism by imaging $\mathrm{F}$ in FDG trapped as FDG6P in brain tissue, in situ with subcellular resolution. The approach was validated in the retina, known for its laminar structure with varying cell composition and then extended to the periventricular hypothalamus, showing that radial glia from both regions take up and phosphorylate glucose.

We first discuss the validation of the LEXRF fluorine signal in retinal and hypothalamic preparations. We then discuss how LEXRF detection of $F$ might be extended even further and how XRF imaging of DG6P differs from previous approaches. Finally, we discuss the challenges encountered in specimen processing for X-ray measurements.

To validate the application of LEXRF to brain tissue metabolism, the uptake of FDG was measured in the dark-adapted (metabolically active) retina, known for its laminar structure and gradient in glucose metabolism, ascribed predominantly to glial Müller cells (PoitryYamate and Tsacopoulos, 1991). Overall, the correspondence between Figure $3 \mathrm{~b}$ and $\mathrm{c}$, as well as among regions $1-3$ in Figure $3 \mathrm{c}$ and $\mathrm{d}$, indicates a disproportionately high uptake and metabolism of glucose by glia compared with photoreceptor neurons. As can be seen from Figures $3 \mathrm{c}$ and $4 \mathrm{~b}$, localized, high intensities of $\mathrm{F}$ matched the structural position of individual endfeet-either facing the vitreous or apposing vessel walls - and radial stalks of Müller glia (Fig. 3a), thereby 
demonstrating the predominantly glial metabolism of glucose in the retina. The high-energy metabolism of the retina, phototransduction, and aerobic production of lactate from glucose (Ola et al., 2006; Poitry-Yamate and Pournaras, 2011) make this light-sensing part of the CNS a highly specialized, if not unique, region, metabolically and functionally, and do not necessarily reflect glucose metabolism in other cerebral regions, i.e., cortex, hypothalamus, hippocampus. Moreover, the LEXRF results do not preclude oxidative ATP formation by retinal glia during net synthesis of glutamate and glutamine, which, when blocked by anoxia (Winkler et al., 2008) or methionine sulfoximine (Barnett et al., 2000), suppresses the b-wave of the electroretinogram.

To extend the previous measurements in the retina to other brain regions, we measured uptake of FDG in the hypothalamus, focusing on the regions lining the third ventricle $(3 \mathrm{~V})$, known to be progressively low in glial content, i.e., tanycytes (Fig. 5e), with increasing distance from the $3 \mathrm{~V}$ (Garcia et al., 2003). Interestingly, $\mathrm{F}$ in FDG-6P (Fig. 5b,c) appeared to correspond to the reported spatial distribution of glucose transporters at the cell soma and stalks (Garcia et al., 2003), likely reflecting the observation that free glucose content is regionally constant (Poitry-Yamate et al., 2009) and thus transporter expression matches tissue metabolic activity. Distant to the $3 \mathrm{~V}$, where glial content is low, $\mathrm{F}$ was at the limits of detection (region 1, Fig. 5b,c), an indication that neuronal energy metabolism may indeed depend in this region on fuel transport from tanycytes, the preferential glucose consumers.

The methodology developed for this study is based on soft X-ray fluorescence imaging, in which the use of $\mathrm{X}$-rays of wavelengths between 2 and $10 \mathrm{~nm}$ (i.e., 200$1,000 \mathrm{eV})$, the well-defined fluorescence cross-sections, and the high brightness of the synchrotron source allow obtaining element-specific information in the submicrometer domain, down to $50 \mathrm{~nm}$, depending on elemental concentration and characteristic X-ray energy. For a low-Z element such as $\mathrm{F}$, the penetration depth of the incident photons is $\leq 2 \mu \mathrm{m}$; the spatial resolution achievable in-plane was thus essentially limited by the sensitivity of the detector and dwell time. Although the latter increases sensitivity according to the square-root law, the number of detectors can in principle be increased. Such increases in sensitivity would allow reducing the number of incident photons and dwell time. This consideration would be of great interest with regard to the data sets of the present study, in which relatively long dwell times were necessary to achieve reasonable photon statistics. This compromise took into account the diffractive optics, the photon flux, the beam in decay mode, and particularly the number of SDDs, at the expense of a data acquisition time of $\sim 18-20$ continuous hours per specimen. Such long acquisition times precluded LEXRF mapping of $\mathrm{F}$ at multiple time points in multiple retinae to calculate rates of retinal glucose utilization.

Two major characteristics distinguish synchrotronbased X-ray imaging from conventional autoradiographic techniques (Geary et al., 1985). First, XRF imaging identifies and quantitates the signal specific to $F$ at 676 $\mathrm{eV}$ and directly within the context of its cellular environment (Figs. 3c-e, 4b,c), as opposed to $\beta$-radiation onto emulsion films apposed to specimen sections in autoradiography. Second, LEXRF elemental maps can be simultaneously placed within a morphological context by performing X-ray absorption imaging (STXM) in parallel (Figs. 1e, 5a), which allowed us to identify cellular structures, used as landmarks. Another difference is the nature of the isotope and its stimulus onset: as opposed to radioisotopes, e.g., ${ }^{18} \mathrm{~F}$, whose decay cannot be controlled, the stable ${ }^{19} \mathrm{~F}$ isotope within the specimen is illuminated (stimulated) by the synchrotron light beam in a time and spatially controlled fashion, building up a spatial $\mathrm{F}$ map by recording the $\mathrm{F}$ photon signal pixel by pixel. Finally, as opposed to single detection using ${ }^{3} \mathrm{H}$, ${ }^{14} \mathrm{C}$, or ${ }^{18} \mathrm{~F}$, multiple detection of elements within the specimen using XRF is possible, whether they are exogenous or endogenous in origin. This was illustrated in the LEXRF map of carbon (Fig. 5d), revealing neuronal somata distant to the $3 \mathrm{~V}$-hypothalamus interface. The emission energy of $F$ is next to that of elements of biological interest, offering an attractive potential strategy different from and beyond STXM to characterize brain cell types and cytoarchitecture further.

Imaging ${ }^{19} \mathrm{~F}$ in ${ }^{19} \mathrm{FDG}-6 \mathrm{P}$ in the brain can potentially be performed with analytical techniques that do not require the use of a synchrotron (for review see Ortega et al., 2009). These techniques fall into two families. The first family makes use of an electron microprobe coupled either to an energy dispersive detector and transmission electron microscopy (Ralle and Lutsenko, 2009) or to electron energy loss spectroscopy. The second family makes use of a proton microprobe, coupled to either particle-induced X-ray emission (Ortega et al., 2005) or the backscattering of particles. An exciting possibility is to combine a number of such analytical methods (Carmona et al., 2008), but this has yet to be performed with brain slices.

Because of the low-energy fluorescence emission of $\mathrm{F}$ photons, the X-ray fluorescence signal from $\mathrm{F}$ may potentially suffer from self-absorption artefacts, which translates into an increased signal intensity loss from the tissue surface to deeper levels within $3-\mu \mathrm{m}$-thick brain sections. If self-absorption was a significant problem, then we should have seen nonlinearity (Sitko, 2009; Szczerbowska-Boruchowska, 2012) in F detection from $2-3-\mu$ m-thick layers of FDG standards. As shown in Figure $2 \mathrm{~d}$, this was not the case.

Any fixation procedure will introduce artefacts into the specimen, and morphometric changes, such as shrinkage, may occur during fixation, dehydration, infiltration, and polymerization (Hayat, 1981). The choice to use formalin as a cross-linking reagent (Ramos-Vara, 2005) was based on its qualities for fluorescence microscopy and short fixation times; formalin does not precipitate proteins or destroy lipids and can be used for longterm storage of biological tissue. Chemical fixation was 
performed before tissue dehydration, rather than in parallel, to minimize possible tissue shrinkage. Permeabilization of cell membranes by the use of detergents, e.g., digitonin, saponin, Triton $\mathrm{X}$, or DMSO, was not employed in the present study. To a first approximation, we assessed the quality of the fixed preparations, e.g., hypothalamus, by comparing the STXM images (Fig. 5a) with confocal images of glucose transporter and GFAP (glial) staining of tanycytes at the hypothalamus-3V interface (see Figs. 3 and 4 in Garcia et al., 2003).

Measurements at the experimental X-ray beamline currently require the removal of tissue water. Consequently, a challenge common to performing histochemistry and autoradiography of biological tissue was probably encountered in this study: the conversion of a soluble constituent of the cell, such as DG-6P, into an insoluble derivative. Retaining FDG-6P in the tissue without degrading morphology were both objectives. However, because nonphosphorylated FDG was expressly removed by washing and/or left ventricle infusion immediately after the metabolic experiment, the unfortunate side effect was that some FDG-6P was inevitably lost in this process (see, e.g., Sokoloff et al., 1977; Nehlig et al., 2004) prior to LEXRF detection of F. This loss would be of major importance only if it occurred in a cell-specific manner, e.g., as suggested by the demonstration of mRNA for aralar in freshly isolated astrocytes (Lovatt et al., 2007) and its absence in synaptosomal-free brain mitochondria (Berkich et al., 2007). With regard to the two regions selected for the present study, spatial LEXRF mapping of ${ }^{19}$ FDG-6P in brain areas closely resembling the general cerebral architecture are underway as part of a separate study. The preliminary results suggest FDG uptake and phosphorylation into neuronal cell bodies, which renders the possibility of FDG-6P loss uniquely from neurons unlikely.

With regard to the known rates of glucose utilization in the retina, derived from the formation of tritiated water from $\left[5-{ }^{3} \mathrm{H}\right]$ glucose $(\sim 25 \mathrm{nmol} / \mathrm{min} / \mathrm{mg}$ protein; Ola et al., 2006) or $2-\left[6-{ }^{13} \mathrm{C}\right]$ deoxyglucose and ${ }^{13} \mathrm{C}-$ NMR spectroscopy $(0.6 \mu \mathrm{mol} / \mathrm{min} / \mathrm{g}$; Cohen et al., 2002), one could derive à priori the rate of global glucose utilization in the rat retina using dynamic ${ }^{18} \mathrm{FDG}$ PET imaging. However, two factors limit the success of such measurements. 1) Unlike the case for cerebral regions, the spatial resolution as a result of positron diffusion $(1 \mathrm{~mm})$ exceeds the thickness of the retina. 2) Spill-in of metabolized ${ }^{18}$ FDG from the Harderian glands occurs. Alternatively, compartmentation of retinal glucose metabolism and rates of change of retinal ${ }^{19} \mathrm{FDG}$ could be determined as described for cerebral regions by McDougal et al. (1990). However, such measurements are incapable of providing information by cell type.

LEXRF imaging of specimens in vitro is presently limited for four reasons: First, in the case of hydrated and unfixed preparations at room temperature, the required imaging dose of radiation is much higher for low-Z elements, i.e., $\mathrm{C}, \mathrm{O}, \mathrm{N}$, and $\mathrm{F}$, than it is for high- $Z$ elements (Fayard et al., 2009), and the issue becomes collecting the fluorescence signal on a time scale that is significantly shorter than the time scale of potentially induced biological damage. Second, and more important, incident X-ray photons upon absorption in aqueous biological specimens result in water molecules being ionized, producing free radicals. Third, there is possible dehydration of the specimen. Fourth, $\mathrm{X}$-rays in the photon energy range used in the present study have limited penetration (less than the thickness of a single cell), limiting the potential interest in performing LEXRF measurements with hydrated specimens.

We conclude that LEXRF is a novel and complementary imaging approach for studying brain metabolism in situ and that glucose metabolism is largely glial in retina and periventricular hypothalamus. Coupled to the subcellular resolution capabilities and the quantitative nature of elemental detection, synchrotron-based LEXRF and STXM together hold remarkable potential for assessing FDG metabolism in regions more closely resembling the general cerebral cytoarchitecture of mature brain. The validation of this imaging modality in the lightsensing and glucose-sensing regions of the CNS demonstrates a high glycolytic activity of radial glia.

\section{ACKNOWLEDGMENTS}

We are grateful to Dr. Maya Kiskinova at ELETTRA for her outstanding scientific and logistical support and critical reading of the manuscript, Prof. Giorgio Margaritondo at the EPFL for his critical reading of an earlier version of the manuscript and financial contribution to the purchase of four SDDs, and veterinarian Hanne Frenkel for technical support. The authors have no conflicts of interest to disclose.

\section{REFERENCES}

Alberti R, Klatka T, Longoni A, Bacescu D, Marcello A, De Marco A, Gianoncelli A, Kaulich B. 2009. Development of a low-energy X-ray fluorescence system with sub-micrometer spatial resolution. X-Ray Spectr 38:205-209.

Barnett NL, Pow DV, Robinson SR. 2000. Inhibition of Muller cell glutamine synthetase rapidly impairs the retinal response to light. Glia 30:64-73.

Berkich DA, Ola MS, Cole J, Sweatt AJ, Hutson SM, LaNoue KF. 2007. Mitochondrial transport proteins of the brain. J Neurosci Res 85:3367-3377.

Carmona A, Deves G, Ortega R. 2008. Quantitative micro-analysis of metal ions in subcellular compartments of cultured dopaminergic cells by combination of three ion beam techniques. Anal Bioanal Chem 390:1585-1594.

Caro LG. 1962. High-resolution autoradiogaphy. II. The problem of resolution. J Cell Biol 15:189-199.

Caro LG, Van Tubergen RP, Kolb JA. 1962. High-resolution autoradiography. I. Methods. J Cell Biol 15:173-188.

Chih CP, Lipton P, Roberts EL Jr. 2001. Do active cerebral neurons really use lactate rather than glucose? Trends Neurosci 24:573-578.

Cohen DM, Wei J, O’Brian Smith E, Gao X, Quast MJ, Sokoloff L. 2002. A method for measuring cerebral glucose metabolism in vivo by ${ }^{13}$ C-NMR spectroscopy. Magn Reson Med 48:1063-1067.

David C, Kaulich B, Barrett R, Salomé M, Susini J. 2000. High-resolution lenses for sub-100 nm X-ray fluorescence microscopy. Appl Phys Lett 77:3851-3853. 
Fayard B, Salome M, Takemoto K, Kihara H, Susini J. 2009. Some practical considerations about the effects of radiation damage on hydrated cells imaged by X-ray fluorescence microscopy. J Electron Spectrosc Rel Phenomena 170:19-24.

Frackowiak RSJ, Magistretti PJ, Shulman RG, Altman JS, Adams M. 2002. Neuro-energetics: relevance in functional brain imaging. Strasbourg: Human Fronteirs Science Program.

Garcia MA, Millan C, Balmaceda-Aguilera C, Castro T, Pastor P, Montecinos H, Reinicke K, Zuniga F, Vera JC, Onate SA, Nualart F. 2003. Hypothalamic ependymal-glial cells express the glucose transporter GLUT2, a protein involved in glucose sensing. J Neurochem 86:709-724.

Geary WA 2nd, Toga AW, Wooten GF. 1985. Quantitative film autoradiography for tritium: methodological considerations. Brain Res 337:99-108.

Gianoncelli A, Kaulich B, Alberti R, Klatka T, Longoni A, de Marco A, Marcello A, Kiskinova M. 2009. Simultaneous soft X-ray transmission and emission microscopy. Nucl Instruments Methods Physics Res Section A Accelerators Spectrom Detectors Assoc Equip 608:195-198.

Hayat MA. 1981. The production of artifacts. Ultrastruct Pathol 2:93; discussion 93.

Hoefler H, Streli C, Wobrauschek P, Ovari M, Zaray G. 2006. Analysis of low $\mathrm{Z}$ elements in various environmental samples with total reflection X-ray fluorescence (TXRF) spectrometry. Spectrochim Acta Part B Atomic Spectrosc 61:1135-1140.

Ide-Ektessabi A. 2007. Applications of synchrotron radiation micro beams in cell microbiology and medicine. Berlin: Springer.

Kaulich B, Bacescu D, Susini J, David C, Di Fabrizio E, Morrison GR, Charalambous P, Thieme J, Wilhein T, Kovac J, Cocco D, Salomé M, Dhez O, Weitkamp T, Cabrini S, Cojoc D, Gianoncelli A, Vogt U, Podnar M, Zangrando M, Zacchigna M, Kiskinova M. 2006. TwinMic-A European Twin X-Ray Microscopy Station commissioned at ELETTRA. Proc 8th Int Conf X-ray Microscopy, IPAP Conf Series 7:22-25.

Kaulich B, Thibault P, Gianoncelli A, Kiskinova M. 2011. Transmission and emission X-ray microscopy: operation modes, contrast mechanisms and applications. J Physics Condensed Matter 23.

Knoechel R, Kalff J. 1976. Applicability of grain density autoradiography to quantitative-determination of algal species production-critique. Limnol Oceanogr 21:583-589.

Lovatt D, Sonnewald U, Waagepetersen HS, Schousboe A, He W, Lin JH, Han X, Takano T, Wang S, Sim FJ, Goldman SA, Nedergaard M. 2007. The transcriptome and metabolic gene signature of protoplasmic astrocytes in the adult murine cortex. J Neurosci 27:12255-12266.

McDougal DB Jr, Ferrendelli JA, Yip V, Pusateri ME, Carter JG, Chi MM, Norris B, Manchester J, Lowry OH. 1990. Use of nonradioactive 2-deoxyglucose to study compartmentation of brain glucose metabolism and rapid regional changes in rate. Proc Natl Acad Sci U S A 87:13571361.

Meents A, Gutmann S, Wagner A, Schulze-Briese C. 2010. Origin and temperature dependence of radiation damage in biological samples at cryogenic temperatures. Proc Natl Acad Sci U S A 107:1094-1099.

Müller RO. 1972. Spectrochemical analysis by X-ray fluorescence. New York: Plenum Press.

Nehlig A, Wittendorp-Rechenmann E, Lam CD. 2004. Selective uptake of $\left[{ }^{14} \mathrm{C}\right] 2$-deoxyglucose by neurons and astrocytes: high-resolution microautoradiographic imaging by cellular ${ }^{14} \mathrm{C}$-trajectography combined with immunohistochemistry. J Cereb Blood Flow Metab 24:10041014.
Ola MS, Berkich DA, Xu Y, King MT, Gardner TW, Simpson I, LaNoue KF. 2006. Analysis of glucose metabolism in diabetic rat retinas. Am J Physiol Endocrinol Metab 290:E1057-E1067.

Ortega R, Fayard B, Salome M, Deves G, Susini J. 2005. Chromium oxidation state imaging in mammalian cells exposed in vitro to soluble or particulate chromate compounds. Chem Res Toxicol 18:1512-1519.

Ortega R, Cloetens P, Deves G, Carmona A, Bohic S. 2007. Iron storage within dopamine neurovesicles revealed by chemical nano-imaging. PLoS One 2:e925.

Ortega R, Deves G, Carmona A. 2009. Bio-metals imaging and speciation in cells using proton and synchrotron radiation X-ray microspectroscopy. J R Soc Interface 6(Suppl 5):S649-S658.

Penner-Hahn JE. 2000. X-ray microprobe imaging and X-ray microscpectroscopy in biology. Synchrotron Radiation News 5:22-30.

Phelps ME. 2000. Positron emission tomography provides molecular imaging of biological processes. Proc Natl Acad Sci U S A 97:92269233.

Poitry-Yamate C, Pournaras C. 2011. Metabolic interactions between neurons and glial cells. In: Levin LA, Nilsson SFE, Hoeve J, Wu SM, editors. Adler's physiology of the eye, 11th ed. Edinburgh: Saunders Elsevier. p 308-324.

Poitry-Yamate C, Tsacopoulos M. 1991. Glial (Muller) cells take up and phosphorylate $\left[{ }^{3} \mathrm{H}\right] 2$-deoxy-D-glucose in mammalian retina. Neurosci Lett 122:241-244.

Poitry-Yamate C, Lei H, Gruetter R. 2009. The rate-limiting step for glucose transport into the hypothalamus is across the blood-hypothalamus interface. J Neurochem 109(Suppl 1):38-45.

Ralle M, Lutsenko S. 2009. Quantitative imaging of metals in tissues. Biometals 22:197-205.

Ramos-Vara JA. 2005. Technical aspects of immunohistochemistry. Vet Pathol 42:405-426.

Ryan AF, Sharp FR. 1982. Localization of $\left[{ }^{3} \mathrm{H}\right] 2$-deoxyglucose at the cellular level using freeze-dried tissue and dry-looped emulsion. Brain Res 252:177-180.

Sitko R. 2009. Quantitative X-ray fluorescence analysis of samples of less than "infinite thickness": difficulties and possibilities. Spectrochim Acta Part B Atomic Spectrosc 64:1161-1172.

Smith K. 2010. Neuroscience: settling the great glia debate. Nature 468:160-162.

Sokoloff L, Reivich M, Kennedy C, Des Rosiers MH, Patlak CS, Pettigrew KD, Sakurada O, Shinohara M. 1977. The $\left[{ }^{14} \mathrm{C}\right]$ deoxyglucose method for the measurement of local cerebral glucose utilization: theory, procedure, and normal values in the conscious and anesthetized albino rat. J Neurochem 28:897-916.

Solé VA, Papillon E, Cotte M, Walter P, Susini J. 2007. A multiplatform code for the analysis of energy-dispersive X-ray fluorescence spectra. Spectrochim Acta Part B Atomic Spectrosc 62:63-68.

Streli C, Kregsamer P, Wobrauschek P, Gatterbauer H, Pianetta P, Pahlke S, Fabry L, Palmetshofer L, Schmeling M. 1999. Low Z total reflection X-ray fluorescence analysis-challenges and answers. Spectrochim Acta Part B Atomic Spectrosc 54:1433-1441.

Szczerbowska-Boruchowska M. 2012. Sample thickness considerations for quantitative X-ray fluorescence analysis of the soft and skeletal tissues of the human body-theoretical evaluation and experimental validation. X-Ray Spectrom 41:328-337.

Winkler BS, Starnes CA, Twardy BS, Brault D, Taylor RC. 2008. Nuclear magnetic resonance and biochemical measurements of glucose utilization in the cone-dominant ground squirrel retina. Invest Ophthalmol Vis Sci 49:4613-4619. 